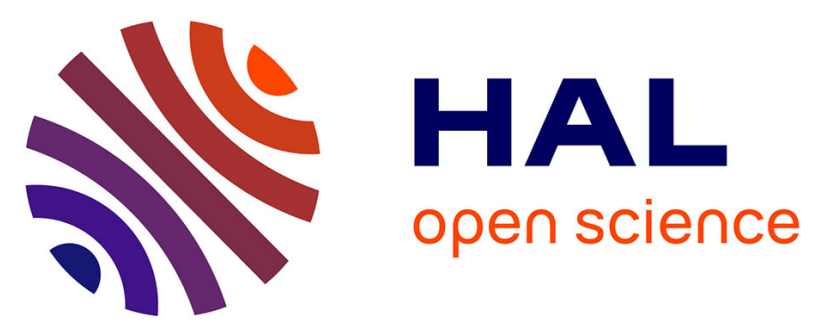

\title{
Goal priming, public transportation habit and travel mode selection: The moderating role of trait mindfulness
}

Jean-Baptiste Légal, Thierry Meyer, Antonia Csillik, Pierre-André Nicolas

\section{To cite this version:}

Jean-Baptiste Légal, Thierry Meyer, Antonia Csillik, Pierre-André Nicolas. Goal priming, public transportation habit and travel mode selection: The moderating role of trait mindfulness. Transportation Research Part F: Traffic Psychology and Behaviour, 2016, 38, pp.47-54. 10.1016/j.trf.2016.01.003 . hal-01292378

\section{HAL Id: hal-01292378 https://hal.science/hal-01292378}

Submitted on 7 Jan 2019

HAL is a multi-disciplinary open access archive for the deposit and dissemination of scientific research documents, whether they are published or not. The documents may come from teaching and research institutions in France or abroad, or from public or private research centers.
L'archive ouverte pluridisciplinaire HAL, est destinée au dépôt et à la diffusion de documents scientifiques de niveau recherche, publiés ou non, émanant des établissements d'enseignement et de recherche français ou étrangers, des laboratoires publics ou privés. 


\title{
Goal priming, public transportation habit and travel mode selection: The moderating role of trait mindfulness
}

\author{
Jean-Baptiste Légal, Thierry Meyer, Antonia Csillik, Pierre-André Nicolas
}

\section{Introduction}

Among the most habitual overt behaviors occurring recurrently in a stable context, transportation would probably be ranked in the top 10, along with eating, working, and sleeping. Indeed, using a travel mode is one of the most habitual behaviors people routinely perform. Imagine you just got a new job. In order to go to your new office for the first time, you have to choose a travel mode (own car, car sharing, bus, bicycle, railway, etc.). In that situation, you can either scrutinize available modes of transportation as a function of one or more attributes (distance, travel frequency, monetary cost, speed, comfort, social reputation, risk level, etc.) or even imitate the majority's choice, follow the advice of your neighbor, or be persuaded by the advertising campaign of a public transportation company. After this deliberative phase, perhaps you decide to use your car to reach your workplace. As you execute this daily behavior, the chosen transportation mode becomes a firmly established habit, leading you to quickly and easily select this transportation mode rather than any other. In the end, a simple smell of coffee in the morning may become a sufficient cue to remind you that it is time to start your car and drive to your office. 


\section{Habits and automaticity}

If habits in transportation have been largely investigated, the concept of habit stems from the history of psychological science. Habits can be defined as "learned dispositions to repeat past responses. They are triggered by features of the context that have covaried frequently with past performance, including performance places, preceding actions in a sequence, and particular people. Context activates habitual responses directly, without the mediation of goal states" (Wood \& Neal, 2007, p. 843). In short, habits refer to near-automatic choices or behaviors in stable contexts (Neal, Wood, \& Quinn, 2009; Neal, Wood, Wu, \& Kurlander, 2011; Ouellette \& Wood, 1998; Verplanken, 2010; Verplanken \& Aarts, 1999; Wood \& Neal, 2007).

From a decision-making point of view, habits have both benefits and pitfalls (Neal, Wood, \& Drolet, 2013). First of all, once they are well established, using habits requires few cognitive resources. Indeed, literature about habits in transportation (Aarts, Verplanken, \& van Knippenberg, 1997; Banister, 1978; Chen \& Chao, 2011; Fujii \& Gärling, 2007; Gärling \& Axhausen, 2003; Gärling, Fujii, \& Boe, 2001; Joireman et al., 1997; Verplanken, Aarts, \& van Knippenberg, 1997; Verplanken, Walker, Davis, \& Jurasek, 2008) broadly documents that the choice of a transport mode required few cognitive resources when people repeatedly used a mode of transportation in a given context. If you take your car every day from your home garage to your workplace, you don't weigh the pros and cons of travel modes every morning, unless an important change occurs in the context that focuses your attention on your choice. Conversely, a stable context and a satisfactory cost/benefit ratio lead to a scripted decision-making mode. Habitual users also need fewer attributes to decide, and are more resistant to other interfering tasks at hand (Aarts et al., 1997). Another self-regulatory benefit of habit is that people can use their free mind space to concentrate on other issues. For instance, before and/or during their transportation time, people can plan their next professional meeting and, in a global fashion, can be more open to their present environment. At odds, habits have some pitfalls when their presence leads people to miss the benefits of new opportunities. Habits have been successfully introduced in social cognitive models of prediction of behavior, as they make a specific contribution to behavioral intentions or behaviors (Chen \& Chao, 2011). Nevertheless, travel choice remains a deliberate decision when people have to change their current habits, as in the context of an intervention that persuades them to change (Bamberg, Ajzen, \& Schmidt, 2003).

From a cognitive point of view, people learn, from repeated choices, to connect a place (i.e., where to go) and a travel mode (i.e., how to reach this place). In other words, through time and experience, people develop strong links in memory between places and travel modes that allow them to reach these places. By means of associative networks, people can rapidly decide on a transportation mode at a low cognitive cost. For habitual travelers, as place-travel modes' associations are very accessible in memory, a place, a goal, or an activity can automatically trigger the choice of a given travel mode. Other travel options are not scrutinized.

Experimental demonstration of automaticity in habits is substantially grounded on the effect of nonconscious primes on decision-making and behavior (e.g., Bargh, 2006, 2014). In the case of daily behaviors, Neal, Wood, Labrecque, and Lally (2012) observed that priming places leads individuals to quickly recognize words related to an activity they regularly perform in these places. For example, priming the word "forest" led participants habitually exercising in woody areas to shorter recognition times for the word "running". This was not the case with more abstract words, even when they were related to the ultimate goal of the behavior (in this example, "to be in good health"). In the transportation domain, as far as we know, only Aarts and Dijksterhuis (2000a, 2000b) provided a demonstration of automaticity in decision-making among habitual users of a transportation mode. They observed that students in the Netherlands, where cycling is a widely used transportation mode, responded faster to bicycle-related words upon the presentation of the word "university" when the goal "to attend lectures at the university" was previously nonconsciously primed. The magnitude of this effect increased with habit strength, measured as the frequency of use of the bicycle to reach target locations (e.g., "university"). In other words, habit strength moderates the effect of nonconscious goal priming.

In sum, previous research indicated that when a means is strongly associated with a goal, the mere activation of a place or a goal activates the corresponding habitual means' mental representation that, in turn, triggers the behavior. One might wonder if individual differences occur in such effortless or automatic effects of habits. Moderation by individual variables is plausible when measurement goes beyond questions focused on explicit and reasoned intentions (Conner et al., 2007). Many choices are driven by contextual cues, but we are more or less able to purposely use these cues to pursue our current goals. As research on mindfulness (e.g., Brown, Creswell, \& Ryan, 2015; Brown \& Ryan, 2003) points out individual differences in the way people trade off between their current goal(s) and their attention to environmental cues, we will focus here on this concept as a source of differences in the ability to process and utilize contextual cues.

\section{Mindfulness and decision making}

In the framework of Self-Determination Theory (Deci \& Ryan, 1985), Brown and Ryan (2003) suggest that mindfulness covers a specific sense of situational awareness and openness to experience. More precisely, Brown and Ryan (2003, p. 822) define mindfulness as "an open or receptive attention to and awareness of ongoing events and experience"; in other words, individuals' ability for "being attentive to and aware of what is taking place in the present". Individuals in the general population reliably differ in their propensity to be mindful (e.g., Brown \& Ryan, 2003; Carlson \& Brown, 2005). Two forms of mindfulness have been operationalized. Dispositional mindfulness refers to stable individual differences concerning average 
levels of mindfulness across time; whereas, state mindfulness concerns systematic fluctuations above and below a person's average level of mindfulness. Although dispositional and state effects of mindfulness on experience are theorized as separate constructs, individuals scoring higher on dispositional mindfulness are more likely to experience higher levels of momentary mindfulness over time (Brown \& Ryan, 2003). Among the many ways in which mindfulness is operationalized (Davidson, 2010), we will focus on dispositional mindfulness. Dispositional mindfulness has demonstrated both conceptual and empirical worth in recent years, and has been associated with a variety of positive outcomes. Empirical research showed that, due to the tendency to evaluate future situations in non-threatening ways, dispositional mindfulness predicts higher well-being and more adaptive stress processing. Furthermore, mindfulness is positively associated with openness to experience, attention, and internal state awareness. Conversely, it is negatively related to social anxiety (Brown \& Ryan, 2003). Mindfulness may also promote more adaptive cognitive appraisals, as it involves a greater willingness or ability to process internal stimuli as they occur, and it fosters more objectively informed responding (Weinstein, Brown, \& Ryan, 2009). A short training in mindfulness (e.g., concentration and breathing exercise) is sufficient to increase the quality of decision making. For example, mindful people are less prone to the sunk cost bias (the tendency to overestimate past unrewarding investments in future decision making; Hafenbrack, Kinias, \& Barsade, 2013).

To date, surprisingly, effects of dispositional mindfulness on habits and more generally, cue driven behaviors, remain underexplored. Studies analyzed the way mindfulness moderates the link between behavior and a more or less deliberate motivation. For instance, mindfulness can provide unique predictions in the framework of dual processes models of thinking (Strack \& Deutsch, 2004) that focus on the interplay between a reflective (or propositional) and an impulsive (associative) mode of thinking. Chatzisarantis and Hagger (2007) also found that deliberate intentions predicted physical activity among mindful individuals, but not among less mindful participants. Interestingly, they concluded that the mindfulness construct catches specific effects that were not confounding with habits. As mindfulness is linked with a greater sense of autonomy and control, it was suspected that mindful individuals could be less responsive to priming manipulation than les mindfull individuals. Radel, Sarrazin, Legrain, and Gobancé (2009), using a proxy of mindfulness measurement, found that priming a learning goal ( $v s$. a performance goal) increased performance - as predicted by goal achievement literature - but only among less mindful participants. This interaction between students' level of dispositional mindfulness and priming condi-tions indicated that, whereas the less mindful participants were affected by priming, the more mindful tended to be immune to the manipulation. Levesque and Brown (2007) observed a similar pattern about an implicit motivation to autonomy that was manipulated through an Implicit Association Test (IAT; Greenwald \& Nosek, 2008). Mindfulness, focusing on implicit awareness, also moderates the link between a nonconscious prime and food choice (fruit vs. chocolate bar). In sum, literature provides evidence of a moderating role of mindfulness in implicit and explicit decision-making, and we think that mindfulness could be useful to document, explain, and predict individual differences in habits.

\section{Present research}

The objective of the present study was twofold. First, we attempted to replicate results concerning priming effects in travel mode selection in habitual users (Aarts \& Dijksterhuis, 2000a, 2000b) and extend them to another transportation mode. We think that a process-based replication is useful considering the complexity of the transportation domain. Transportation means are very dissimilar as a function of multiple attributes (ownership, availability, complexity, cost, risk perception, social norms, etc.) that can interfere with the habit process. For example, as ownership is associated with the self, it could be expected that ownership of a travel means increases the accessibility of this very travel means in memory (Wood \& Neal, 2009). So, a replication with a public transportation mode (subway) would broaden the evidence of automaticity-based selection of transportation modes among habitual users. Second, and most importantly, our aim was to investigate to what extent effortless or automatic effects of habits and priming are susceptible in individual differences. If habitual choices are driven by subtle contextual cues, we may be more or less able to purposely use these cues to pursue our current goals. That is why we investigated whether or not dispositional mindfulness (as a source of individual difference in awareness and attention) could moderate the direct association between cues and travel mode choice. For these purposes, we observed how more or less mindful and habitual users of a subway line select a transportation mode after being nonconsciously primed with a proximal travel goal that could be reached by subway.

As stated earlier, day-to-day repetition of behaviors in a stable context has a cognitive consequence: cues in the environment become sufficient to trigger decisions without extensive deliberation. In the transportation domain, and especially modal choice, habits are firmly established. If people are conscious of the result of their choice, they are not necessarily aware of the processes underlying their decision (Bargh, 2014). Precisely, the processing of a contextual cue (e.g., a concrete travel goal) can either follow a deliberative path with a conscious travel goal that drives modal choice; or a more direct, associative, or habitual path that does not need to be mediated by a conscious goal. For habitual users of a travel mode, the accessibility of a cue (e.g., the name of a place, an activity, or a goal) is sufficient to elicit a regular means of travel. Conversely, people with no travel habits need to associate the cue and a deliberate travel goal in order to select and adopt a travel mode. From this point of view, habit strength should be a good predictor of a less deliberative mode of thinking. According to previous research (e.g., Aarts \& Dijksterhuis, 2000a, 2000b), having a place or an activity in mind is sufficient to find and select a travel mode. Thus, priming a travel goal that is firmly linked with a transportation mode should speed the decision to select the habitual travel mode. 
We also posit that people can make transportation choices in a more or less mindful way of thinking. As mindfulness refers to the degree to which a person is receptive to present experience, participants with higher levels of mindfulness should take more advantage of cues present in their environment to decide among transportation options. Specifically, since the association between a place and a travel mode is firmly established among habitual users, we hypothesize that habitual users of a trans-portation means, whatever their level of dispositional mindfulness, would be more able to quickly decide on a travel mode as a function of an accessible contextual cue. For them, a high level of mindfulness would only marginally facilitate response to con-textual cues. On the contrary, non-habitual users should be more dependent on their level of mindfulness. As less mindful indi-viduals are supposed to have a lower ability to purposefully process mental or environmental events, a low level of mindfulness could puzzle over the link between available environmental cues and travel mode. In other words, we assume that a low level of mindfulness should hinder the use of the associations between cues and transport means in the decision-making process. Con-versely, non-habitual users with a high level of mindfulness should benefit more from useful cues in the environment.

In sum, this study tested the effect of priming travel goals to specific places as a function of habit strength and level of mindfulness on the time subsequently required to decide whether or not a travel mode fits with a given place or activity. Following previous observations (Aarts \& Dijksterhuis, 2000a, 2000b), priming should shorten response times more among habitual users than non-habitual users (H1: interaction between priming and habit strength). We also expected that mindfulness level would moderate this interaction (H2). More precisely, the interaction between priming and habit strength should only be observed among less mindful users. One consequence of this expected pattern is that the benefit of habits in decision-making should be greater for people with a low level of mindfulness.

\section{Material and method}

\subsection{Participants and context}

Undergraduate students ( $N=86 ; M_{\text {age }}=20 ; 80 \%$ women) were recruited and filled out a consent form. They received course credits for their participation. The participants studied at Paris Ouest University (France). The area's complex transportation network offers multiple travel modes that can be chosen by users. Public transportation to the university is afforded by a large station (more than 60000 passengers/day) that combines a suburban subway station and a railway line. The university can also be reached through several bus lines as well as by using main and secondary roads by car, motorcycle and/or cycle, or on foot.

\subsection{Variables}

\subsubsection{Transportation habits}

In terms of measurement, habits are generally considered as reports of frequent - ordinary daily - behaviors in stable contexts. Beyond self-reports of past behavior, habits can be measured not only as overt actions, but also as mental events (i.e., a subjective experience that is associated with frequent and well-learned behaviors; Verplanken, 2010). A few weeks before the experiment, we measured transportation habits during a mass testing session. We assessed habits through the conjunction of reported past behavior's frequency (number of days of subway use) and stability of context, assessed by subjective experience of frequency (Verplanken \& Orbell, 2003). Participants reported: (1) how many times a week they used the subway (using an open-ended question) and (2) their agreement with the fact they use the subway on a day-to-day basis (using a 5-point Likert scale ranging from 1: Totally disagree to 5: Totally agree). We combined these two measures $(r=.51, p<.01)$ to create a habit score. We used a median split procedure to separate habitual vs. non-habitual users of the subway. Habitual users reported using the subway about 11 times a week $(M=10.5, S D=4.9)$ whereas non-habitual users reported using it about 4 times a week $(M=3.7, S D=1.5), F(1,82)=74.2, p<.0001, \eta^{2}=.48$.

\subsubsection{Priming}

A Scrambled Sentence Task (SST; e.g., Chartrand \& Bargh, 1996; Srull \& Wyer, 1979) was used to prime concrete travel goals. In the goal-priming condition, all the sentences included a place that was associated with the use of the subway line (e.g., going to the university). Processing those sentences thus activated this travel means (i.e., subway) in the memory (Aarts \& Dijksterhuis, 2000b). In the control condition, sentences to unscramble were about an activity that was neutral in regard to travelling and using the subway (e.g., playing the piano).

\subsubsection{Mindfulness}

Participants filled out the Mindful Attention Awareness Scale (MAAS; Brown \& Ryan, 2003) as a part of a mass testing session. The MAAS is a 15-item scale, assessing the frequency of open attention to, and awareness of, internal states and external events in the present, using both general and situation-specific statements (e.g., I find it difficult to stay focused on what's happening in the present). The MAAS measures mindfulness by asking respondents to rate the frequency with which their day-to-day consciousness reflects this quality. Higher scores on the scale indicate greater mindfulness. The MAAS has been extensively validated and used in a number of previous studies (Brown, Ryan, \& Creswell, 2007). In this research, we used an original French translation (Csillik, Mahr, \& Meyer, 2010) that replicated the original one-factor structure. 


\subsection{Procedure}

When arriving at the lab, participants were informed that they would participate in two unrelated studies. The first one was presented as a language test, and the second one as a survey about travel preferences. In the first part, participants were randomly handed one version of the scrambled sentence task (place-priming version or control version) in which they had to arrange words given in a random order to build sentences. After completing this task, participants moved on to the travel preferences study that consisted of a computer-driven task adapted from Aarts and Dijksterhuis (2000b). In this task, participants were presented with 5 target places (university, Australia, shopping center, library, and airport) and had to decide as quickly as possible if the travel mode displayed on the screen (subway, bicycle, plane, bus, or pedestrian) was appropriate or not to reach the place. Pre-test indicated that among the 5 concrete travel goals, 3 had a strong subjective association with the use of the subway line (airport, university, and shopping center). After 5 training trials, participants completed 25 test trials in which the 5 places were randomly assigned to each of the 5 travel modes. Decision times were recorded (in milliseconds). Finally, participants completed a funneled debriefing questionnaire (Bargh \& Chartrand, 2000) in order to probe the detection of a link between the studies by participants, as well as any potential influence of the first task on the second one. No participants guessed the link between the scrambled sentence task and the travel preferences study.

\subsection{Results}

We conducted a $2 \times 2$ mixed analysis of covariance (ANCOVA) with Priming and Habits, respectively, as manipulated and observed categorical predictors. Z-standardized MAAS scores served as a quantitative predictor (Aiken \& West, 1991) in a full factorial design. Response times to the three concrete travel goals (airport, university, and shopping center) were introduced as a within-subject factor (Target).

First, we analyzed the data for the three places considered altogether (see Fig. 1). Response times were shorter for primed participants $(M=1285 \mathrm{~ms}, S D=424 \mathrm{~ms})$ than for participants in the control condition $(M=1123 \mathrm{~ms}, S D=425 \mathrm{~ms}), F(1,78)$ $=6.2, p=.016, \eta^{2}=.073$. Habitual users of the subway line displayed shorter response times $(M=1086 \mathrm{~ms}, S D=60 \mathrm{~ms})$ compared to non-habitual users $(M=1293 \mathrm{~ms}, S D=59 \mathrm{~ms}), F(1,78)=2.9, p=.094, \eta^{2}=.035$. Level of mindfulness was negatively but not significantly related to response times $F(1,78)=2.76, p=.11, \eta^{2}=.033$. Interaction between Priming and Habit, $F(1$, $78)=2.9, p=.045, \eta^{2}=.05$, indicated that only habitual users were influenced by the priming manipulation (Scheffé post hoc test, $p=.032$ ). The Priming $\times$ Mindfulness $\times$ Habit interaction, $F(1,78)=6.00, p=.017, \eta^{2}=.072$, pointed out that the priming effect was moderated by mindfulness when habit strength was low. Priming induced shorter response times in participants having a high score on the mindfulness scale, but increased response times among participants with a low score on mindfulness. When habit strength was high, goal priming led to shorter response times, no matter what the mindfulness score was. The same pattern of interaction was observed when habit was introduced in the model as a continuous variable rather than a dichotomous variable, $F(1,78)=9.8, p<.0025, \eta^{2}=.11$.

We also conducted two separate ANOVAs, respectively for low and high levels of mindfulness. For those demonstrating low levels of mindfulness, the interaction between habit and goal priming was significant, $F(1,36)=11.4, p<.002, \eta^{2}=.24$. Travel goal priming decreased the speed of response to subway when habit was strong (post hoc Scheffé, $p<.022$ ), but not when habit was weak (post hoc Scheffé, $p<.50$ ). For those demonstrating high levels of mindfulness, habits and priming contributed as main effects, respectively $F(1,42)=2.1, p<.051$ and $F(1,42)=2.9, p<.099$. There were no interactions between factors.

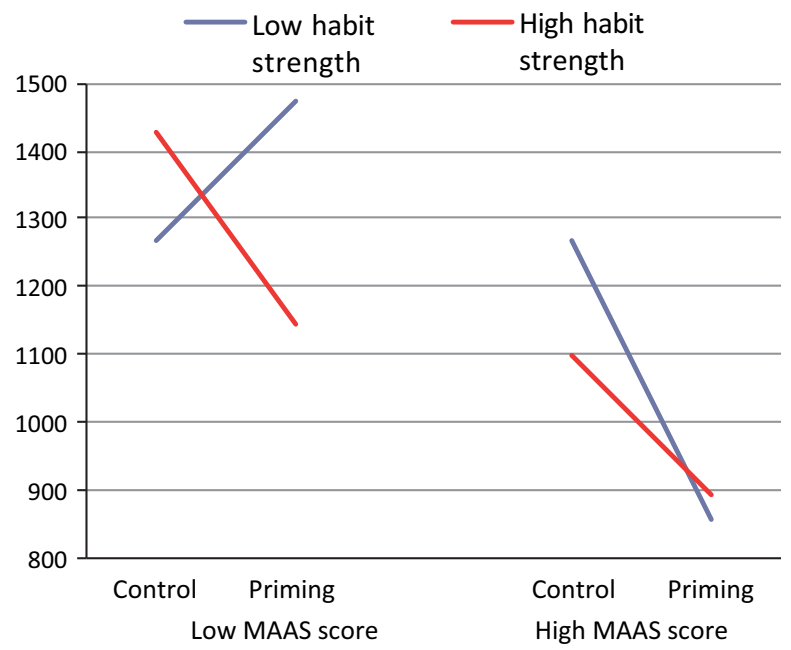

Fig. 1. Response times (in ms) as a function of goal priming, habit strength and mindfulness score (regression lines). 
Considering the three target travel goals (airport, university, and shopping center) as a within factor, response times were faster for University ( $M=974 \mathrm{~ms} ; S D=308$ ) than for Airport and Shopping center (respectively $M=1347 \mathrm{~ms}, S D=615$ and $M=1292 \mathrm{~ms}, S D=683), F(2,156)=14.7, p=.0001, \eta^{2}=.159$. Analyses yielded a significant Priming $\times$ Habit interaction, $F$ $(2,156)=3.17, p=.045, \eta^{2}=.040$, as well as a Priming $\times$ Habit $\times$ MAAS interaction, $F(2,156)=3.42, p=.03, \eta^{2}=.042$. These results indicated that the previous observations were less significant for University compared to the other places (longer response times). To illustrate this pattern, we performed separate ANOVAs for each place. For participants with a low mindfulness score, the interaction between Habits and Priming remained significant for Airport $\left(F(1,78)=6.72, p=.011, \eta^{2}=.079\right)$ and Shopping Center $\left(F(1,78)=5.96, p=.017, \eta^{2}=.071\right)$, and was marginally significant for University $(F(1,78)=3.42$, $p=.065, \eta^{2}=.042$ ).

\subsection{Discussion}

From an ecological point of view, our laboratory task captures decisions in a specific environment (a Parisian university and its transportation network), and for a specific travel mode (a subway line) and a specific task (deciding on a travel mode). Corroborating internal validity of the habit construct as an automatic mode of action control, a concrete travel goal (i.e., where to go) can automatically activate transportation means (i.e., how to travel) among habitual users. Only habitual users of a public transportation means needed less time to select this travel mode, as the transportation goal was nonconsciously primed comparing to a condition with no prime (H1). Globally, and even the measurement of habit strength is slightly different from previous observations (Aarts \& Dijksterhuis, 2000a, 2000b), the replication of this pattern from a domain (private transportation: bicycle) to another domain (public transportation: subway) ensures the robustness of the effect and of underlying processes. Beyond adding a small piece of external validity, our main purpose was to explore the moderating role of dispositional mindfulness (as measured by MAAS), considering the interaction between travel goal priming and habit strength. The expected interaction between habit strength and priming was found only at low levels of mindfulness. At high levels of mindfulness, habits and travel goal contributed additively to decision making, as if participants were able to separate previous habits from a contextual inner cue (priming manipulation). Thus, the three-way interaction hypothesis is confirmed (H2). Considering the speed of decision for a travel mode, habits appear to benefit more to less mindful participants than to mindful participants. For participants with low levels of mindfulness, habits compensate the disturbing effect of nonconscious primes. As observed by Neal et al. (2013) in a depletion of self-control framework, habits can improve goal adherence when self-control is low. As they indicate that habits follow different paths as a function of dispositional mindfulness, our results confirm the interest of the mindfulness construct to explore the flexibility of the habit processes. These results also contribute to the exploration of the processes of automaticity in habits, which are far from being fully understood (Wood, Labrecque, Lin, \& Rünger, 2014).

\section{Limitations and perspectives}

Further studies are needed to explore the process of decision making in habitual context in regards of mindfulness. For instance, do people with a high level of mindfulness develop habits earlier compared to people with a low level of mindfulness? In this research, we considered mindfulness a trait. Yet, mindfulness can change within individuals as a function of the task, moment, age, or the learning of meditation techniques (Davidson, 2010). Even if further research is needed to explore this issue, we expect that changes in mindfulness within people would result in the same pattern of results as in the current study. Beyond mindfulness, related concepts such as mind wandering (Mrazek et al., 2012, 2013) should also be of interest. As travel mode becomes a firmly grounded habit based on a day-to-day behavioral repetition, modal change is a very difficult issue for policy makers (Gärling \& Axhausen, 2003). From this point of view, habits have benefits, but also pitfalls when they lead people to miss the benefits of new opportunities. Indeed, the dark side of habits is to sustain inaction, because people don't consider other available options (Gifford, 2011), or they even fall in lapses when they maintain old habits even when having in mind a new conscious goal (Reason \& Mycielska, 1982). Interventions focus either on maintaining good habits or changing bad habits. Following our results, such intervention may consider habit as a construct where individual differences in decision making matter. From this point of view, mindfulness could be a barrier to change, as it raises habits; but also an opportunity for change, as mindful people are more able to resist impulsive decisions and use the present information when this information is congruent with their present goal. Behavioral interventions based on minor changes in the proximal context have gained popularity, with the promise to improve decision making beyond deliberated reasoning (Thaler \& Sunstein, 2009). Our results emphasize the need to better understand individual differences in near-automatic decision-making processes. Indeed, subtle cues or minor changes in the environment did not benefit all participants, but only the ones who already had habits in place, and the ones with a high level of mindfulness. Badly designed cues could impair decision making among people with no habits and a low level of mindfulness (i.e., people who are less able to adjust their attention to their current environment for purposeful action). Recognizing that many people experience difficulties in focusing their attention on congruent cues could prevent paradoxical effects of policy interventions. Nevertheless, travel choice remains a deliberate decision when people have to change their current habits, as in the context of an intervention that persuades them to change (Bamberg et al., 2003) or an unplanned change in the decision framework. For instance, a major increase in gas price could make alternative transportation options more attractive than your car. In such a disrupting case, 
you could be more aware of a discrepancy between your car-use habit and your personal preference for car, your financial needs or your pro-environmental values (Verplanken et al., 2008). Therefore, exploring the role of dispositional mindfulness at more deliberative levels of decision making would be useful. Finally, interventions focusing on metacognitive insight about one's automatic response to transportation choice could be explored. The extensive literature about change in mindfulness (Brown et al., 2015) could open interesting paths for changing or maintaining habits in the real-world context.

\section{References}

Aarts, H., \& Dijksterhuis, A. (2000a). Habits as knowledge structures: Automaticity in goal-directed behavior. Journal of Personality and Social Psychology, 78 , 53-63.

Aarts, H., \& Dijksterhuis, A. (2000b). The automatic activation of goal-directed behaviour: The case of travel habit. Journal of Environmental Psychology, 20, $75-82$.

Aarts, H., Verplanken, B., \& van Knippenberg, A. (1997). Habit and information use in travel mode choices. Acta Psychologica, 96, 1-14.

Aiken, L. S., \& West, S. G. (1991). Multiple regression: Testing and interpreting interactions. Thousand Oaks: Sage.

Bamberg, S., Ajzen, I., \& Schmidt, P. (2003). Choice of travel mode in the theory of planned behavior: The roles of past behavior, habit, and reasoned action. Basic and Applied Social Psychology, 25, 175-188.

Bargh, J. A., \& Chartrand, T. L. (2000). The mind in the middle: A practical guide to priming and automaticity research. In H. T. Reis \& C. M. Judd (Eds.), Handbook of research methods in social and personality psychology (pp. 253-285). New York: Cambridge University Press.

Banister, D. (1978). The influence of habit formation on modal choice - A Heuristic model. Transportation, 7, 5-33.

Bargh, J. A. (2006). What have we been priming all these years? On the development, mechanisms, and ecology of nonconscious social behavior. European Journal of Social Psychology, 36, 147-168.

Bargh, J. A. (2014). Our unconscious mind. Scientific American, 310, 30-37.

Brown, K. W., Creswell, J. D., \& Ryan, R. M. (Eds.). (2015). Handbook of mindfulness theory, research, and practice. New York: Guilford.

Brown, K. W., \& Ryan, R. M. (2003). The benefits of being present: Mindfulness and its role in psychological well-Being. Journal of Personality and Social Psychology, 84, 822-848.

Brown, K. W., Ryan, R. M., \& Creswell, J. D. (2007). Mindfulness: Theoretical foundations and evidence for its salutary effects. Psychological Inquiry, 18, 211-237.

Carlson, L. E., \& Brown, K. W. (2005). Validation of the Mindful Attention Awareness Scale in a cancer population. Journal of Psychosomatic Research, 58, 29-33.

Chartrand, T. L., \& Bargh, J. A. (1996). Automatic activation of impression formation and memorization goals: Nonconcious goal priming reproduces effects of explicit task instructions. Journal of Personality and Social Psychology, 71, 464-478.

Chatzisarantis, N. L. D., \& Hagger, M. S. (2007). Mindfulness and the intention behavior relationship within the theory of planned behavior. Personality and Social Psychology Bulletin, 33, 663-676.

Chen, C.-F., \& Chao, W.-S. (2011). Habitual or reasoned? Using the theory of planned behavior, technology acceptance model, and habit to examine switching intentions toward public transit. Transportation Research Part F: Traffic Psychology and Behaviour, 14, 128-137.

Conner, M., Perugini, M., O'Gorman Ayres, K., \& Prestwich, A. (2007). Relations between implicit and explicit measures of attitudes and measures of behavior: evidence of moderation by individual difference variables. Personality and Social Psychology Bulletin, 33, 1727-1740.

Csillik, A. S., Mahr, S., \& Meyer, T. (2010). The Mindful Attention Awareness Scale (MAAS) French validation: convergent and divergent validity. In Fourth meeting of the social determination theory society. Ghent University: Belgium.

Davidson, R. J. (2010). Empirical explorations of mindfulness: Conceptual and methodological conundrums. Emotion, 10, 8-11.

Deci, E. L., \& Ryan, R. M. (1985). Intrinsic motivation and self-determination in human behavior. New York: Plenum Publishing Co.

Fujii, S., \& Gärling, T. (2007). Role and acquisition of car use habits. In T. Gärling \& L. Steg (Eds.), Threat from car traffic to the quality of urban life: Problems, causes, and solutions (pp. 235-247). Amsterdam: Elsevier.

Gärling, T., Fujii, S., \& Boe, O. (2001). Empirical tests of a model of determinants of script-based driving choice. Transportation Research Part F, 4, 89-102.

Gärling, T., \& Axhausen, K. W. (2003). Habitual travel choice. Transportation, 30, 1-11.

Gifford, R. (2011). The dragons of inaction: Psychological barriers that limit climate change mitigation and adaptation. American Psychologist, 66, 290-302.

Greenwald, A. G., \& Nosek, B. A. (2008). Attitudinal dissociation: What does it mean? In R. E. Petty, R. H. Fazio, \& P. Briñol (Eds.), Attitudes: Insights from the new implicit measures (pp. 65-82). Hillsdale, NJ: Lawrence Erlbaum Associates.

Hafenbrack, A. C., Kinias, Z., \& Barsade, S. G. (2013). Debiasing the mind through meditation: Mindfulness and the sunk-cost bias. Psychological Science, 25, 369-376.

Joireman, J. A., Van Lange, P. A. M., Kuhlman, D. M., Van Vugt, M., \& Shelley, G. P. (1997). An interdependence analysis of commuting decisions. European Journal of Social Psychology, 27, 441-463.

Levesque, C., \& Brown, W. N. (2007). Mindfulness as a moderator of the effect of implicit motivational self-concept on day-to-day behavioural motivation. Motivation \&' Emotion, 31, 284-299.

Mrazek, M. D., Franklin, M. S., Phillips, D. T., Baird, B., \& Schooler, J. W. (2013). Mindfulness training improves working memory capacity and GRE performance while reducing mind wandering. Psychological Science, 24, 776-781.

Mrazek, M. D., Smallwood, J., \& Schooler, J. W. (2012). Mindfulness and mind-wandering: Finding convergence through opposing constructs. Emotion, 12, $442-448$.

Neal, D. T., Wood, W., \& Drolet, A. (2013). How do people adhere to goals when willpower is low? The profits (and pitfalls) of strong habits. Journal of Personality and Social Psychology, 104, 959-975.

Neal, D. T., Wood, W., Labrecque, J. S., \& Lally, P. (2012). How do habits guide behavior? Perceived and actual triggers of habits in daily life. Journal of Experimental Social Psychology, 48, 492-498.

Neal, D. T., Wood, W., \& Quinn, J. M. (2009). Habits: A repeat performance. Current Directions in Psychological Science, 15, 198-202.

Neal, D. T., Wood, W., Wu, M., \& Kurlander, D. (2011). The pull of the past: When do habits persist despite conflict with motives? Personality and Social Psychology Bulletin, 37, 1428-1437.

Ouellette, J. A., \& Wood, W. (1998). Habit and intention in everyday life: The multiple process by which past behavior predicts future behavior. Psychological Bulletin, 124, 54-74.

Radel, R., Sarrazin, P., Legrain, P., \& Gobancé, L. (2009). Subliminal priming of motivational orientation in educational settings: Effect on academic performance moderated by mindfulness. Journal of Research in Personality, 43, 695-698.

Reason, J. T., \& Mycielska, K. (1982). Absent minded? The psychology of mental lapses and everyday errors. Englewood Cliffs, NJ: Prentice Hall.

Srull, T. K., \& Wyer, R. S. (1979). The role of category accessibility in the interpretation of information about persons: Some determinants and implications. Journal of Personality and Social Psychology, 37, 1660-1672.

Strack, F., \& Deutsch, R. (2004). Reflective and impulsive determinants of social behavior. Personality and Social Psychology Review, 8, $220-247$.

Thaler, R. H., \& Sunstein, C. R. (2009). Nudge: Improving decisions about health, wealth, and happiness. New York: Penguin Books.

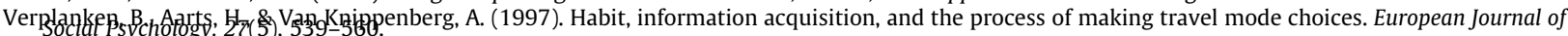


Verplanken, B. (2010). Habit: From overt action to mental events. In C. R. Agnew, D. E. Carlston, W. G. Graziano, \& J. R. Kelly (Eds.), Then a miracle occurs: Focusing on behavior in social psychological theory and research (pp. 68-88). New York: Oxford University Press.

Verplanken, B., \& Aarts, H. (1999). Habit, attitude, and planned behaviour: Is habit an empty construct or an interesting case of goal-directed automaticity? European Review of Social Psychology, 10, 102-134.

Verplanken, B., \& Orbell, S. (2003). Reflections on past behavior: A self-report index of habit strength. Journal of Applied Social Psychology, 33, 1313-1330.

Verplanken, B., Walker, I., Davis, A., \& Jurasek, M. (2008). Context change and travel mode choice: Combining the habit discontinuity and self-activation hypotheses. Journal of Environmental Psychology, 9, 15-26.

Weinstein, N., Brown, K. W., \& Ryan, R. M. (2009). A multi-method examination of the effects of mindfulness on stress attribution, coping, and emotional well-being. Journal of Research in Personality, 43, 374-385.

Wood, W., Labrecque, J. S., Lin, P. Y., \& Rünger, D. (2014). Habits in dual process models. In J. W. Sherman, B. Gawronski, \& Y. Trope (Eds.), Dual-process theories of the social mind (pp. 371-385). New York: Guilford.

Wood, W., \& Neal, D. T. (2007). A new look at habits and the habit-goal interface. Psychological Review, 114, $843-863$.

Wood, W., \& Neal, D. T. (2009). The habitual consumer. Journal of Consumer Psychology, 4, 579-592. 